Portland State University

PDXScholar

\title{
A study of the capability of the computerized Visi- Pitch when investigating prosodic features of motherese
}

Denise Leslie Clemens

Portland State University

Follow this and additional works at: https://pdxscholar.library.pdx.edu/open_access_etds

Part of the Speech Pathology and Audiology Commons

Let us know how access to this document benefits you.

\section{Recommended Citation}

Clemens, Denise Leslie, "A study of the capability of the computerized Visi-Pitch when investigating prosodic features of motherese" (1988). Dissertations and Theses. Paper 3743.

https://doi.org/10.15760/etd.5627

This Thesis is brought to you for free and open access. It has been accepted for inclusion in Dissertations and Theses by an authorized administrator of PDXScholar. Please contact us if we can make this document more accessible: pdxscholar@pdx.edu. 
AN ABSTRACT OF THE THESIS OF Denise Leslie Clemens for the Master of Science in Speech Communication: Emphasis in Speech-Language Pathology presented October 27, 1988.

Title: A study of the Capability of the Computerized VisiPitch When Investigating Prosodic Features of Motherese.

APPROVED BY MEMBER OF THE THESIS COMMITTEE:
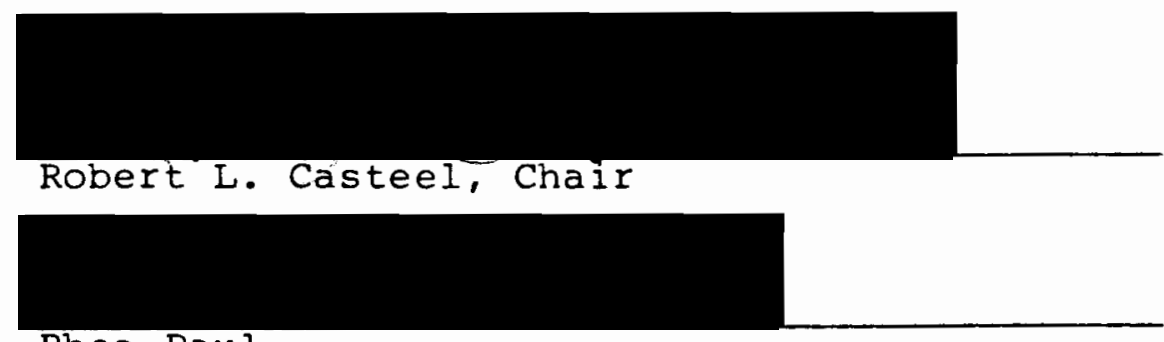

Rhea Paul

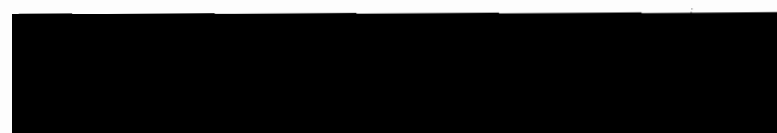

Steve A. Grannan

With commercial availability of non-real and real-time spectrum analyzers, the speech-language pathologist has the means to objectively extract and measure pitch taken from speech samples. Though both types of spectrum analyzers provide the clinician with viable methods of measuring fundamental frequency and frequency range values, pitch extraction using real time allows for greater efficiency in acoustic measurements. The Kay Elemetrics Visi-Pitch is one such real-time spectrum analyzer that is less expensive and 
more accessible than other real time speech science hardware. The purpose of this study was to investigate the capability of a computerized Visi-Pitch to reflect elevation of fundamental frequency and expansion of frequency range by female adults.

Ten mothers and ten non-mothers, between the ages of 20 and 40 , were used as subjects in the study. In addition to this subject group, ten of the mother's infants between the ages of 4.0 and 8.0 months of age were used as listeners in the study. Sixty second speech samples were elicited from the female adults while they spoke to: 1) the investigator, and 2) the infant. Forty seconds of these samples were analyzed through a computerized Visi-Pitch in order to determine average fundamental frequency (pitch) and frequency range in each speaking situation.

Analysis of fundamental frequency revealed that both adult subject groups (mothers and non-mothers) elevated their pitch when addressing the child, in comparison to the adult-adult interaction. A one-tailed t-test for dependent measures was used to determine the significant difference between average fundamental frequency used by mothers when addressing the infant and the adult. The same type of $t$ test was used to determine differences between average fundamental frequency used by non-mothers when addressing the child and the adult. Statistical analysis revealed that 
for the average of the ten mothers fundamental frequency, pitch used when addressing the child was not significantly higher than pitch used to the adult. The average pitch used by mother subjects when addressing the child was elevated by $15 \mathrm{~Hz}$. In terms of fundamental frequency outcomes used by non-mothers addressing the two listeners, it was found that non-mothers elevated their pitch by an average of $36.8 \mathrm{~Hz}$, a statistically significant difference.

A t-test for independent measures was used when comparing mothers and non-mothers fundamental frequency when addressing the adult listener. Statistical analysis of the data revealed no significant difference between mothers and non-mothers use of pitch when speaking to the adult. Similarly, analysis of pitch levels used by mothers (228.7 $\mathrm{Hz}$ ) and non-mothers $(243.8 \mathrm{~Hz})$ when addressing the infant listener was found not to be statistically significant. While it appeared that the computerized Visi-Pitch allows for comparison and analysis of fundamental frequency data, the instrument provided questionable frequency range results. Low points of frequency range were not subjected to statistical analysis due to spurious data points at the low end of frequency range, which exceeded the known range of normal adult female voices.

Results of this study revealed that the real time computerized Visi-Pitch has the capability to demonstrate 
the use of adult female pitch shifting in the same direction as other motherese studies; however, it was found that this instrument is an inadequate tool for frequency range analysis.

It was concluded that more solid evidence on the validity of frequency range outcomes needs to be disseminated by the Visi-Pitch manufacturer before this instrument can be considered of value to the researcher. 
A STUDY OF THE CAPABILITY OF THE COMPUTERIZED

\title{
VISI-PITCH WHEN INVESTIGATING PROSODIC
}

FEATURES OF MOTHERESE

by

DENISE LESLIE CLEMENS

A thesis submitted in partial fulfillment of the requirements for the degree of

\author{
MASTER OF SCIENCE \\ in \\ SPEECH COMMUNICATION \\ with emphasis in \\ SPEECH-LANGUAGE PATHOLOGY
}

Portland State University

1988 
TO THE OFFICE OF GRADUATE STUDIES:

The members of the Committee approve the thesis of Denise Leslie Clemens presented October $27,1988$.

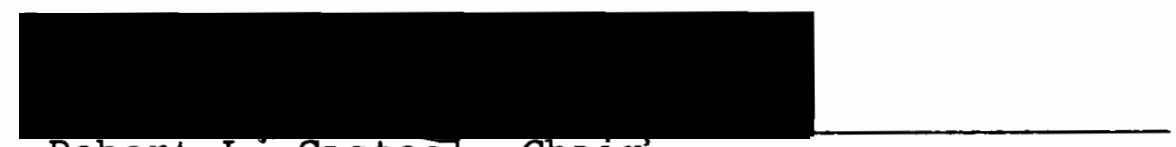

Robert L. Casteel, Chair

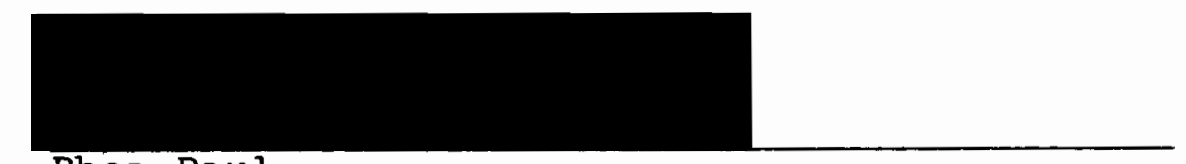

Rhea Paul

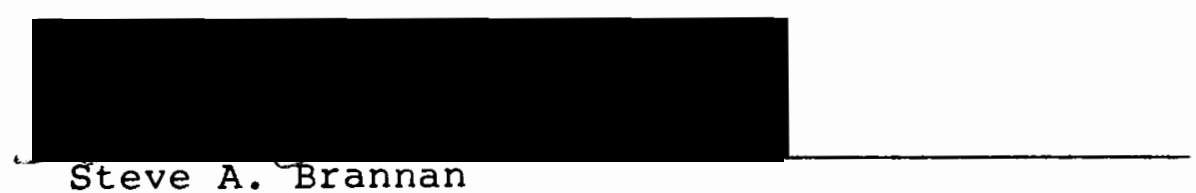

Steve A. Brannan

APPROVED :

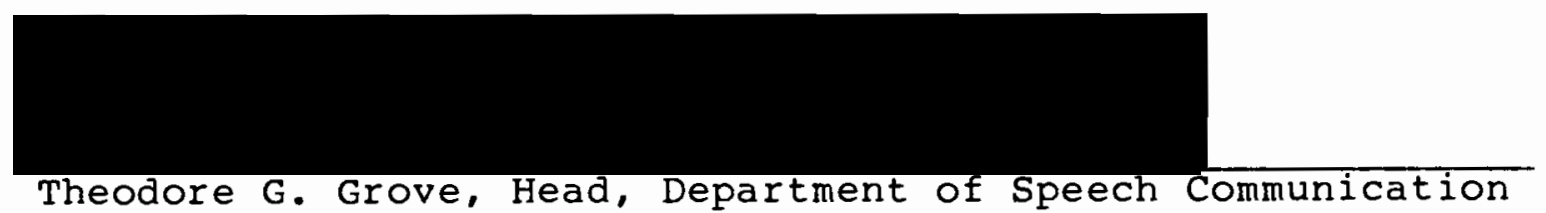




\section{ACKNOWLEDGEMENTS}

I would like to extend my deep appreciation to Robert Casteel, Ph.D. and Rhea Paul, Ph.D., who guided and supported me throughout this project. To Gary Renschler, $\mathrm{Ph} . \mathrm{D}$. and all the staff at Portland Center for Hearing and speech, I wish to thank you for the use of much of the instrumentation used in this project. Without your assistance, this masters thesis would not be a reality.

I am grateful to Dick Frey and Jim Henry at the Portland V.A. Medical Center for instrumentation and technical assistance during my many "crisis periods." To all the speech Pathology staff at PVAMC, my deepest gratitude for having the patience not only to see me through this project, but also my CFY as well. To the Bardsley family, I would like to express deep gratitude for opening up their hearts and their home.

Finally, I would like to thank my mother, Nancy, who showed the infinite support and encouragement only a mother could give, and Mark, for your unending love and kindness throughout this project and my graduate education. Thank you! 
TABLE OF CONTENTS

PAGE

ACKNOWLEDGEMENTS . . . . . . . . . . . . . iii

LIST OF TABLES . . . . . . . . . . . . . . . vi vi

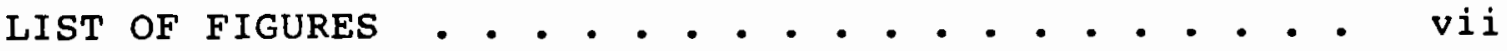

CHAPTER I

I

INTRODUCTION

Statement of Purpose . . . . . . 3

Hypothesis . . . . . . . . 5

Definition of Terms . . . . . . 5

II REVIEW OF THE LITERATURE $\quad . . . . . . .97$

Methods of Measuring

Fundamental Frequency . . . .

Subjective Analysis

Non-Real-Time Spectrum Analyzer

Real-Time Spectrum Analyzer

Summary •. . . . . . . . . 19

II METHODS . . . . . . . . . . 21

Subjects . . . . . . . . . . 21

Instrumentation ....... . 23

Procedures ........... . 26

Verbal Task

Speech Sample 
PAGE

Reliability and Validity . . . . .

Reliability

Validity

Statistical Analysis . . . . . 32

IV

RESULTS

Discussion

$\mathrm{V}$

SUMMARY

48

Implications . . . . . . . . .

BIBLIOGRAPHY 


\section{LIST OF TABLES}

TABLE

PAGE

I Forms of Acoustical Analysis . . . . . . . 8

I Overview of Motherese Literature . • • . . 20

II Adult Subject Information . - . . . . - . . 22

IV Scoresheet for Investigator and Technician Interjudge Reliability . . . . . . . . 29

V Scoresheet for Investigator Intrajudge Reliability . . . . . . . . . . . .

VI Scoresheet for Technician Intrajudge

Reliability . . . . . . . . . . . • .

VII Comparison of Mothers Fundamental Frequency

When Addressing Adults Versus Children • .

VIII Comparison of Non-Mothers Fundamental

Frequency When Addressing Adults Versus

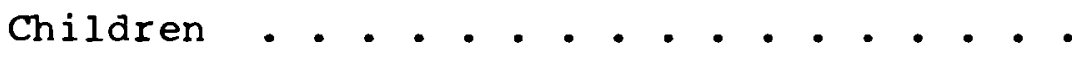

IX Comparison of Mother and Non-Mother

Fundamental Frequency When Addressing

Adults . : . . . . . . . . . . . . .

X Comparison of Mothers and Non-Mothers

Fundamental Frequency When Addressing Children . . . . . . . . . . . . . .

XI Fundamental Frequency Used by Adult Females

In Two Listener Situations . . . . . . . 


\section{LIST OF FIGURES}

FIGURE

PAGE

1. Mean Fundamental Frequency for Mothers Addressing Two Listener Types . . . . .

2. Mean Fundamental Frequency for Non-Mothers Addressing Two Listener Types . . . . . 


\section{CHAPTER I}

\section{INTRODUCTION AND STATEMENT OF PURPOSE}

\section{INTRODUCTION}

Prior to the availability of commercial spectrum analyzers, the Speech-Language Pathologist lacked effective tools to quantitatively measure acoustical parameters of speech. Specifically, fundamental frequency (pitch) could only be assessed using subjective judgements. Subjective decisions were used to determine whether pitch levels were appropriate or inappropriate for: a) speaker's age and sex, b) communicative situation, and c) listener age. Following the judgement by the clinician that a deviation in the use of pitch existed, a treatment program would be initiated. Without adequate means of objectively measuring fundamental frequency and frequency range, gauging progress within a management program was difficult.

With an increase of availability of acoustic analysis systems, the Speech-Language Pathologist could make measurements of fundamental frequency and frequency range much more effectively. Spectrum analyzers have provided the clinician with means to objectively extract and measure fundamental frequency and frequency range data from speech 
samples. Off-line/non-real-time spectrum analyzers and real-time spectrum analyzers have the capacity to precisely extract these two parameters from speech. Though both methods provide viable data, pitch extraction utilizing real time allows for greater efficiency in pitch measurement. The Kay Elemetrics Visi-Pitch is one such real-time analyzer that extracts and measures fundamental frequency and frequency range information from speech.

One aspect of language use that has been analyzed with reference to fundamental frequency and frequency range is the special register used to address very young children. This special register has been known by several names: "motherese," "baby talk," and "child-directed speech" (Berko-Gleason, 1973; Ferguson, 1964; Snow, 1977). Motherese research has illustrated the unique and often dramatic differences between speech directed to adults and speech directed to children. Two prosodic features of motherese that have special relevance and are consistently reported: adults shift fundamental frequency and expand frequency range when speaking to young children. Pitch shifting has long been reported in the literature across styles of speakers (Remick, 1971; Snow and Ferguson, 1977). Researchers who have studied speech directed to babies have noticed that mothers tend to use higher overall pitch levels, as well as expanded ranges when addressing children 
(Berko-Gleason, 1973; Fernald and Simon, 1984; Garnica, 1974 and 1977; Remick, 1971). These features can be found across several languages, including English, Arabic, Spanish Marathi, and Latvian (Drach, 1969; Ferguson, 1964; Kelkar, 1964; Ruke-Dravina, 1977).

These paralinguistic features have been documented through the use of subjective judgement, non-real-time analysis, and real-time spectrum analyzers. The Visi-Pitch is less expensive and more assessable than other real time speech science hardware. There is a need to find appropriate clinical hardware which has a broader availability to clinicians who need to make real time judgements regarding the appropriateness of fundamental frequency and frequency range registers of speech models used in interacting with young children.

\section{STATEMENT OF PURPOSE}

The purpose of this study was to investigate the capability of a real-time computerized Visi-Pitch to reflect elevation of fundamental frequency and expansion of frequency range by female adults when speaking to infants.

This investigation will seek to answer the following questions, with regard to the outcome of computerized VisiPitch results: 
1. Does the average fundamental frequency used by mothers when speaking to infants differ significantly from the average fundamental frequency used in adult-adult interactions?

2. Does the average fundamental frequency used by non-mothers when speaking to infants differ significantly from the average fundamental frequency used in adult-adult interactions?

3. Does the average fundamental frequency used by mothers when speaking to adults differ significantly from the average fundamental frequency used by non-mothers when speaking to adults?

4. Does the average fundamental frequency used by mothers when speaking to children differ significantly from the average fundamental frequency used by non-mothers when speaking to children?

5. Does the frequency range used by mothers when speaking to infants differ significantly from the frequency range used in adult-adult interactions?

6. Does the frequency range used by non-mothers when speaking to infants differ significantly from the frequency range used in adult-adult interactions? 
7. Does the frequency range used by mothers when speaking to adults differ significantly from the frequency range used by non-mothers when speaking to adults?

8. Does the frequency range used by mothers when speaking to children differ significantly from the frequency range used by non-mothers when speaking to children?

\section{HYPOTHESIS}

Since it is well established that pitch shifting in adult speech does occur when young children are addressed, it is hypothesized that, when investigating elevation of fundamental frequency and expansion of frequency range used in child-directed speech, a real time computerized VisiPitch will yield similar results to those found in studies utilizing subjective judgement, non-real time, and other real time forms of analysis.

\section{DEFINITION OF TERMS}

Fundamental Frequency: The lowest frequency component of a complex tone that has the same frequency as the vocal fold's frequency of vibration (Borden and Harris, 1980).

Pitch Shift: The difference, in Hertz, between baseline pitch in adult-adult interactions and pitch data obtained during adult-child interaction. 
Prelinguistic: Within an infant's first year of life when he/she is not using words to communicate intentions (Nicolosi, et al., 1983).

Range: Represents the difference, in Hertz, between the highest and lowest fundamental frequency recorded within an utterance (Stern et al., 1983).

Real Time Spectrum Analyzer: An instrument which displays an almost instantaneous changing spectrum of complex signals (Borden and Harris, 1980). One example of a real time spectrum analyzer is the Kay Elemetrics Visi-Pitch. 


\section{CHAPTER II}

\section{REVIEW OF THE LITERATURE}

\section{METHODS OF MEASURING FUNDAMENTAL FREQUENCY}

In an attempt to quantify acoustic parameters of motherese, researchers have measured fundamental frequency and frequency range utilizing three types of methodology used in acoustical analysis (Table I).

\section{Subjective Analysis}

Subjective analysis of fundamental frequency does not require the use of specific apparatus or instrumentation, rather a subjective decision is made by the listener. Blout and Padgug (1976), as well as the Sachs et al. (1976) study employed the use of subjective judgement to determine pitch levels used by adults when speaking to adult and child listeners.

Blout and Padgug (1976) directed an investigation into parental speech in English and in Spanish. Listeners included nine children (five English children ranging from .9 to 1.6 years and four Spanish children ranging from .8 to 1.1 and from 1.6 to 1.10 years. Tape recorders were sent home with parents on a weekly basis. Parents were asked to record normal verbal interactions with their child during 
TABLE I

FORMS OF ACOUSTICAL ANALYSIS

Subjective

Analysis
Non-Real Time

Spectrum Analysis
Real-Time

Spectrum Analysis
Blout \& Padgug (1976)

Sachs et al. (1976)
Jacobsen et al. (1983)

Remick

(1971)

Garnica (1974, 1977)
Bernstein Ratner

\& Pye (1984)

Stern et al. (1983)

Warren-Leubecker

\& Bohannon (1984)

Fernald \& Simon (1984)

regular times of day. Examination of the parent-child utterances led to the identification of an inventory of 34 prosodic, paralinguistic, and interactional features. Once this inventory was established, each parental utterance was subjectively judged for the presence or absence of specific child-directed features. Analysis of the English sample revealed that exaggerated intonation and high pitch were used most often by parents when speaking to their children (no differentiation was made regarding specific features used by mothers and/or fathers). Spanish parents used repetition and exaggerated intonation most often when 
speaking to their children, employing higher pitch to a lesser degree.

Sachs, Brown, and Salerno (1976) subjectively investigated the speech of five adults (three female, two male) who told a story first to a 22-month-old girl and then to a female adult. Comparison of adult-adult interaction and adult-child speech revealed subjective differences in the speaker's use of pitch. A rise in fundamental frequency as well as increases in pitch changes within a variety of utterances were noted during the adult-child interactions.

\section{Non-Real-Time Spectrum Analyzer}

Non-real-time or off-line spectrum analysis involves recording a segment of speech and playing it over again to perform an acoustical analysis. These types of wave analyzers are designed to analyze and display non-stationary signals. Often the analyzer is capable of printing an acoustical representation of the speech sample (Kay Elemetrics, 1986). A sound spectrograph is one example of an off-line spectrum analyzer.

Jacobsen, Boersma, Fields, and Olson (1983) reported the use of a sound spectrograph when analyzing adult speech to children. They investigated the use of pitch in parents and non-parents addressing children between the ages of 4-8 months and $1.10-2.6$ years. Sixteen male and 16 female adults, half of whom were married and had children, and half 
of whom were single without children, participated in the study. Seven sentences were chosen for analysis from each of the sessions. The selected samples were processed through a Kay Elemetrics Spectrum Analyzer model no. 6061B. Fundamental frequency was measured by hand from the spectrograms using dial calipers and a $1 / 2 \mathrm{~mm}$ rule. Fundamental frequency and variability of fundamental frequency were measured for each data sample. Analysis of the data revealed, in terms of sex differences and types of variations used in speech, females increased both their mean fundamental frequency and average variability across the four stimulus conditions significantly more than males. In terms of experience with children, nonparents increased their average fundamental frequency and average variability as much as parents with extensive child rearing experience. Thus, degrees of experience and "comfort" level with children does not seem to affect the modifications of fundamental frequency in speech to children. Baseline adult-adult values were found to be: males $=123 \mathrm{~Hz}$, females $=209 \mathrm{~Hz}$. Fundamental frequency values increased significantly when adults were asked to imagine speaking to an infant or child (males $=133 \mathrm{~Hz}$, females $=223 \mathrm{~Hz}$ ). When an actual youngster was present, males spoke to the infant with an average of $146 \mathrm{~Hz}$, and to the child with an average of $143 \mathrm{~Hz}$. Females spoke to the infant with an average of 
$255 \mathrm{~Hz}$, and used an average of $245 \mathrm{~Hz}$ when addressing the child. This was the first study designed to document empirically that adults, regardless of sex or parental status, increase mean and variability of their fundamental frequency when speaking to an infant or small child.

Additionally, Remick (1971) calculated median fundamental frequency of mother's speech to children by way of spectrographic analysis. Remick studied speech of ten mothers speaking to their children (ages 1.4 to 2.5 years). She calculated both median fundamental frequency and frequency range from narrow band spectrograms for a subsample of sentences for each subject. Actual fundamental frequency, frequency range, and their standard deviations were not given in the study but were expressed rather by the difference between the quartile values. Utterances were analyzed while mothers addressed: (1) an adult, and (2) their child. Her findings revealed that only the mothers of the youngest children used a higher median fundamental frequency and a greater frequency range when addressing the child. The speech of mothers whose children had already begun to acquire language tended to show a restriction in both median and fundamental frequency range more similar to that seen in adult-adult interactions.

Measurements of fundamental frequency in Garnica's studies $(1974,1977)$ were calculated using a non-real-time 
analysis system. She directed two studies involving children who were producing language. Her 1977 study involved a comparison of adult (mother)-adult interaction and the interaction of an adult (mother)-child (her own twoor five-year-old child). Twenty-four (12 women with a child in the 1.0 to 2.6 range and 12 women with a child in the 5.1-5.7 range) participated in the study. Analysis of data revealed that in comparison with the speech to the adult, speech to the two year old was characterized by a higher average fundamental frequency, a greater frequency range, longer duration of content words, and rising pitch terminals within certain types of sentences. The mean fundamental frequency when speaking to the child listener was elevated to $267.3 \mathrm{~Hz}$, as compared to the mean fundamental frequency of $197.6 \mathrm{~Hz}$ used when addressing the adult listener. The frequency range, especially at the high end was greatly expanded, with many frequencies in the 400-600 $\mathrm{Hz}$ range. Speech to five years olds was characterized by a greater frequency range and longer duration of some content words. Garnica's 1974 study also investigated speech to two- and five-year-old children. In this study Garnica noted that pitch changes at the ends of utterances were more pronounced in speech to two year olds than to five year olds. She also found a greater tonal range (two octaves) when mothers addressed the two year olds, as compared to the one and one- 
half octaves used when talking to an adult. The pitch of the mother subjects was found to be at a higher level than during adult-adult interactions. A fundamental frequency of $267.3 \mathrm{~Hz}$ was found to be used with the two year olds, while a pitch of $200 \mathrm{~Hz}$ was found to be used when talking to the five year olds and the adult.

Real-Time Spectrum Analyzer

Real-time analysis of speech provides the user with an on-line, almost instantaneous spectrum analysis of a speech sample. Thus, it converts a time waveform to the frequency domain (Stemple, 1984). Several prior investigations of fundamental frequency used in maternal speech have employed real time spectrum analyzers in the analysis of speech. Bernstein Ratner and Pye (1984) analyzed fundamental frequency data through the use of a Voice Identification Inc., PM 100 microprocessor-controlled device. This instrument was designed to display intensity and pitch curves on a split-screen display. The microprocessor capacity enables the PM 100 to sum each plotted fundamental frequency value and average the values across each utterance (Bernstein Ratner and Pye, 1984; Stemple, 1984). Bernstein Ratner and Pye noted that mothers who speak the Quiche Mayan language did not use a higher pitch when speaking to their children. Quiche is a Mayan language spoken in the western highland region of Guatemala. Data for this study were 
originally gathered for syntactic and morphological analysis over a nine month period in 1977. Data from three Quiche mothers were compared with data from two English speaking mothers when speaking to their children. Quiche infant listeners ranged from 1.10 to 2.6 years and English infant listeners ranged from 1.8 to 1.9 years. Results of this longitudinal study revealed that the three Quiche mothers used a lower pitch or made no pitch distinction when addressing their children as compared to adult-adult interactions. In contrast, both English mothers increased their pitch by $35-70 \mathrm{~Hz}$ when speaking to their children as compared with the pitch they normally used when speaking to an adult. A PM 100 frequency-intensity analyzer was used to analyze data. However, the tape recordings of the quiche mothers used in this study were originally gathered for syntactic and morphological analysis, not for acoustic analysis. Furthermore, the naturally noisy recording conditions encountered during taping in a rural village environment (chickens, threshing machines, etc.) limited the experimenters to a smaller body of "cleaner" and clearer tapes made during the original study.

Stern, Spieker, Barnett, and MacKain (1983) reported processing maternal speech samples through the Princeton Applied Research, FFT Real-Time Spectrum Analyzer \#4512. This spectrograph was equipped with a narrow band filter 
which allowed for hard copy records of changes in fundamental frequency (Stemple, 1984; Stern et al.. 1983). These authors analyzed age-related changes in the prosodic features of speech to infants at newborn, four, 12, 25 months. Their longitudinal study investigated maternal speech used with their own children and speech addressed to an adult examiner. Infant listening data was taken at the time the infant was: (1) two to six days old, (2) four months old, (3) 12 months old, (4) 24 months old. Maternal speech samples were transcribed and processed through a sound spectrograph. While average fundamental frequency was not investigated, four different pitch events were recorded: Terminal pitch change, transitional pitch change, range, and absolute high. A comparison between infant-directed and adult-directed speech revealed that mothers showed more pitch contouring with her infant than she did with an adult. Maternal speech to infants showed a significantly greater degree of pitch change at the ends of utterances and between utterances. Measures of both range and absolute high indicated a greater degree of contouring in speech to infants. Results reveal that maternal speech to four-monthold infants shows a greater use of certain prosodic features than maternal speech to neonates or to 12 - or 24-month-old infants. Specifically, all measures of pitch and sound repetition showed more extensive/exaggerated use at the four 
month level. Thus, these authors concluded that motherese has been shown to be especially responsive to changes in infant maturation during the first year of life.

In addition to these two studies, Warren-Leubecker and Bohannon (1984) identified fundamental frequency and frequency range using a Unigon Model 4512 real-time spectrum analyzer. These authors attempted to identify and quantify important prosodic features of male and female speech addressing two- and five-year-old children. The speech of 16 mothers and 16 fathers (one-half of the subjects were parents of two year olds, and one-half of the subjects were parents of five year olds). Data was collected on fundamental frequency and frequency range using a Unigon Model 4512 Real time Spectrum Analyzer which was displayed on an oscilloscope. Results of the analysis revealed that when addressing two year olds, mothers as well as fathers significantly increased their modal fundamental frequency; however, fathers increased their modal voice frequency when addressing the younger listener even more than mothers did (mean increase for fathers $=45 \mathrm{~Hz}$; mean increase for mothers $=26 \mathrm{~Hz}$ ). In terms of pitch used, fathers did not differentiate between the five-year-old children and adult listeners. That is, fathers used the same pitch levels when addressing both five-year-old children and adults. Mothers, on the other hand, still showed a significant increase in 
modal frequency $(16.3 \mathrm{~Hz})$ when speaking to the five year olds. Furthermore, mothers used a greater frequency range than fathers when speaking to adult or to the older children. In summary, this study illustrated that fathers, as well as mothers, use exaggerated intonation when speaking to two-year-old children. Mothers continue to use some exaggerated intonation for five year olds, but fathers did not use this prosodic feature.

Fernald and Simon (1984) also used a real-time analyzer in their study of maternal speech. A PDP computer coupled with a pitch extraction program was designed for their study. They examined the speech of 24 German mothers (12 with a first born child, and 12 who had another child), in three interactional situations. Interaction was recorded in conversational speech between: (1) the mother and the experimenter, (2) the mother and her three- to five-day-old infant (which she held in her arms), and (3) the mother alone during a simulated infant-directed interaction in which the mother was instructed to pretend to talk with her baby (infant absent). Tape recordings of each interactional situation were analyzed on a PDP $11 / 45$ computer using a Pitch-Extractor program designed for this particular study. Results revealed that both the experienced and nonexperienced mothers radically modify the normal tonal and temporal patterns of their speech when addressing their 
three- to five-day-old baby. Findings were significant when comparing mother-child speech (mean $=227 \mathrm{~Hz}$ ) and motheradult speech (mean $=203 \mathrm{~Hz}$ ). Mean fundamental frequency was found to be higher (by $55 \mathrm{~Hz}$ ), pitch excursions were greater, utterances shorter, and pauses were longer. In the simulated mother-child interaction, mothers significantly altered the investigated prosodic features, with the exception of fundamental frequency (mean $=201 \mathrm{~Hz}$ ). Analysis of intonational contours revealed that mothers used primarily "expanded" pitch contours when speaking to their newborn infants. That is, mothers use long, smooth, continuous pitch glides with fundamental frequency excursions averaging 13 semitones and sometimes exceeding two octaves in range. This study suggests that extensive previous experience with infants may not be a prerequisite for the occurrence of these prosodic maternal behaviors. One real-time spectrum analyzer that does not appear to have been used in previous studies is the Kay Elemetrics Visi-Pitch which extracts and measures fundamental frequency $(50-1600 \mathrm{~Hz})$ in real time. Speech signals may be analyzed by the instrument which extracts cycle-to-cycle changes in frequency. The speech signal is processed through four circuits and low-pass selected filters. The Visi-Pitch has the capacity to average the number of pitch periods for the previous second of voiced speech and displayed on a LED 
counter (Kay Elemetrics, 1986; Stemple, 1984). This instrument, alone or coupled with a microprocessing computer, does not appear to have been used in prior investigations of pitch shifting in maternal speech. The Visi-Pitch is a real-time spectrum analyzer that is less expensive and more accessible than other real-time analyzers.

\section{SUMMARY}

In summary, research has shown the remarkable ways adults modify various prosodic and paralinguistic features when addressing children. It has been noted that both fundamental frequency and frequency range have been consistently modified by adults when addressing infants and children (Table II).

Measurement of these prosodic variations have occurred through a variety of methods and instrumentation. Subjective analysis, non-real time, and real-time methods of data collection have been utilized in acoustical research. The Visi-Pitch is a real-time analysis instrument that has not been used previously in these studies. 
TABLE I I

OVERVIEW OF MOTHERESE LITERATURE

\begin{tabular}{|c|c|c|c|c|}
\hline Study & Speaker & Listeners & $\begin{array}{c}\text { Tested } \mathbf{F}_{0} \\
\text { Range }\end{array}$ & $\begin{array}{c}\text { Tested } \\
\text { Frequency }\end{array}$ \\
\hline $\begin{array}{l}\text { Garnica } \\
(1974,1977)\end{array}$ & Mothers & $\begin{array}{l}\text { Adults } \\
2 \text { year olds } \\
5 \text { year olds }\end{array}$ & Yes & Yes \\
\hline $\begin{array}{l}\text { Bernstein Ratner } \\
\text { \& Pye (1984) }\end{array}$ & $\begin{array}{l}\text { English \& } \\
\text { Quiche speaking } \\
\text { Mothers }\end{array}$ & $\begin{array}{l}\text { Adults } \\
20-33 \text { months old }\end{array}$ & Yes & No \\
\hline Remick (1971) & Mothers & $\begin{array}{l}\text { Adults } \\
1.4-2.5 \text { year olds }\end{array}$ & Yes & No \\
\hline $\begin{array}{l}\text { Warren-Leubeker } \\
\text { \& Bohannon }\end{array}$ & $\begin{array}{l}\text { Mothers } \\
\text { Fathers }\end{array}$ & $\begin{array}{l}\text { Adults } \\
2 \text { year olds } \\
5 \text { year olds }\end{array}$ & Yes & Yes \\
\hline $\begin{array}{l}\text { Fermald \& } \\
\text { Simon (1984) }\end{array}$ & $\begin{array}{l}\text { German speaking } \\
\text { Mothers }\end{array}$ & $\begin{array}{l}\text { Mothers } \\
\text { 3- } 5 \text { day olds }\end{array}$ & Yes & Yes \\
\hline $\begin{array}{l}\text { Sachs et al. } \\
(1976)\end{array}$ & Non-Parents & $\begin{array}{l}\text { Adults } \\
22 \text { manth olds }\end{array}$ & Yes & No \\
\hline$\underset{(1983)}{\text { Sterm et al. }}$ & Mothers & $\begin{array}{l}\text { Adults } \\
2-6 \text { day olds } \\
4 \text { month olds } \\
12 \text { month olds } \\
24 \text { month olds }\end{array}$ & No & Yes \\
\hline $\begin{array}{l}\text { Jacobsen et al. } \\
\text { (1983) }\end{array}$ & $\begin{array}{l}\text { Mothers } \\
\text { Non-Mothers } \\
\text { Fathers } \\
\text { Non-Fathers }\end{array}$ & $\begin{array}{l}\text { Adults } \\
4-8 \text { month olds } \\
22-30 \text { month olds }\end{array}$ & Yes & No \\
\hline $\begin{array}{l}\text { Blout \& Padgug } \\
\text { (1976) }\end{array}$ & $\begin{array}{l}\text { English \& } \\
\text { Spanish speaking } \\
\text { Mothers }\end{array}$ & $.9-1.1$ year olds & Yes & Yes \\
\hline
\end{tabular}




\section{CHAPTER III}

\section{METHODS}

\section{SUBJECTS}

Subjects included ten mothers, each with a child between ages of 4.0 and 8.0 months, ten infants, and ten adult females who do not have children of their own (nonmothers) (Table III). The subjects were all from the Greater Portland Area who were recruited through ads placed in various areas (Appendix A). The names of mothers were also obtained from interested graduate students and friends. In order to participate in this study, each of the adult subjects (mothers and non-mothers) read a cover letter (Appendix B) and met the following criteria:

1. All adult subjects passed a hearing screening test for the frequencies of 1000, 2000, and 4000 Hz.

2. All adult subjects passed standard English in the home and were judged to have sex-appropriate voices.

3. All adult subjects were between the ages of 20-40 years. 


\section{TABLE III}

ADULT SUBJECT INFORMATION

\begin{tabular}{|c|c|c|c|}
\hline Subject \# & Age & Parental status & Infant Age \\
\hline 1 & 27 & Non-Mother & - \\
\hline 2 & 30 & Mother & 4 months \\
\hline 3 & 27 & Mother & 4 months \\
\hline 4 & 29 & Non-Mother & - \\
\hline 5 & 29 & Non-Mother & - \\
\hline 6 & 32 & Mother & 6 months \\
\hline 7 & 40 & Mother & 7 months \\
\hline 8 & 40 & Non-Mother & - \\
\hline 9 & 32 & Mother & 6 months \\
\hline 10 & 29 & Non-Mother & - \\
\hline 11 & 28 & Mother & 5 months \\
\hline 12 & 25 & Non-Mother & - \\
\hline 13 & 33 & Non-Mother & - \\
\hline 14 & 35 & Mother & 6 months \\
\hline 15 & 29 & Non-Mother & - \\
\hline 16 & 27 & Mother & 8 months \\
\hline 17 & 26 & Mother & 8 months \\
\hline 18 & 27 & Non-Mother & - \\
\hline 19 & 35 & Non-Mother & - \\
\hline 20 & 35 & Mother & 6 months \\
\hline
\end{tabular}

4. All adult subjects with or without a child signed a permission slip (Appendix C) allowing them and (if appropriate) their child to participate in the study.

5. All mother subjects had a child between 4.0 and 8.0 months of age and were willing to have the child participate in the study. 


\section{INSTRUMENTATION}

Tape recordings were made of the ten mothers and the ten non-mothers as they spoke to the examiner and then to the infant. The electronic equipment (Appendix D) was in a suitably quiet, carpeted room. The clinic room was located in the speech and hearing clinic at Portland state University. Apparatus included the Ar-tik' Model 414 tape recorder and the corresponding Ar-tik' brand microphone. The Ar-tik' tape recorder is a specially designed high fidelity reel to reel recorder that operates at a speed of 7 $1 / 2$ ips. The tape recorder was placed in a microphone stand approximately six inches from the speaker's mouth. For the interactional setting of the adult-adult session, the subject sat in a chair across from the examiner. For the adult-child interaction, the infant was placed in a stroller, while the adult subject sat facing the child.

Once the data collection had been completed, the recorded information was transferred to a Tandberg (model 9200XD) reel to reel tape recorder, as the Ar-Tik' playback was noted to have a slow "rise time" unsuitable for visiPitch analysis. The Tandberg interfaced easily with the Kay Elemetrics Visi-Pitch 6087DS that was used in this study. The Visi-Pitch is an electronic instrument which measures the fundamental frequency of an input signal (e.g., the subject's voice) on a cycle-to-cycle basis. The frequency 
readout displays the average fundamental frequency over the last full second of voicing. The integral display screen provides for oscillographic tracing which can be used to track frequency, amplitude, or the two together (Stemple, 1984). For the purposes of this study, the following settings were used: TRIGGER CONTROL/"Normal"; RANGE/"C"; POSITION/"Full"; FUNCTION/ "Fundamental Frequency"; TIME/"2 second." It was necessary to use a two second time frame and the "C" range in order to appropriately interface with the computer. This time frame and frequency range allows the computer to analyze a body of data greater than nine seconds. This study sampled 60 seconds of speech; however, actual data analysis occurred with the middle 40 seconds of the speech sample. Data analysis was achieved by first clearing both the Visi-Pitch and computer CRT screens of previous information. Ten seconds of taped speech were allowed to run without performing any analysis. It was necessary to monitor the last utterance of the first ten seconds of speech in order to anticipate the initiation of the middle 40 seconds of speech. The initiation of data analysis was achieved by simply depressing the Visi-Pitch microphone's on/off switch for the desired 40 seconds. Once the selected data had been introduced into the Visi-Pitch, the IBM PC computer Interface (VP + I) model 6098 and an IBM compatible computer were used to perform 
extensive acoustic analysis of the speech samples (Appendix $E$ and F). A Leading Edge Model D, 20-megabyte hard disk computer (IBM compatible) was used in this study. The computer and the accompanying interface contained a program which had the capacity to calculate average intensity, pitch perturbation, pitch range, and other useful parameters. Three parameters, extended average fundamental frequency, maximum fundamental frequency, and minimum fundamental frequency were extracted from the statistical analysis of the speech sample. The extended average fundamental frequency and frequency range for each of the forty speech samples were displayed on the computer screen and logged. All numerical data were rounded to the nearest whole in order to simplify further statistical analysis (e.g., 212.8 $\mathrm{Hz}$ rounded to $213 \mathrm{~Hz}$ ).

For the purpose of this study, the IBM compatible computer was programmed with the following settings: TIME SELECTION/"9 Seconds"; FORMAT SELECTION/"Pitch and Intensity, Stationary Display"; FREQUENCY SELECTION/ "0-400 Hz." The nine second program was selected to obtain an extended average fundamental frequency and frequency range over the forty second duration of the samples. Initiation of analysis was accomplished by depressing the Visi-Pitch microphone's on/off switch for the amount of time desired 
for data analysis (40 seconds) after elapsed time of ten seconds.

\section{PROCEDURES}

All adult subjects took part in two interactional sessions. Tape recordings were made of the adults as they spoke to the adult interviewer and the infant. The adult interviewer in all cases was the investigator. All subjects spoke first to the investigator then to the child. Both testing sessions took place in a Portland State University clinic room. During the adult-adult session, only the mother (or non-mother) and the experimenter were present in the testing room. For the adult-child session, the mother (or non-mother), the child and the experimenter were present in the testing clinic room. During the few minutes the mother or non-mother were in the first testing room with the examiner, the child remained in the second room with a graduate student or another mother who attended to the child.

\section{Verbal Task}

Subjects were told that the purpose of the study was "to look at the ways adults interact with infants." All subjects were told that they will be asked to talk briefly with the investigator and then to a child. During the adult-adult interaction, subjects were told: "I would like 
you to talk for about one minute about this plastic ball. You can tell me anything about the color, the shape, the size, or any other thing it brings to mind. Please continue describing the object until I tell you to stop" (Appendix G). Immediately following the adult-adult session, the subjects were asked to perform the same task (i.e., describing the object) while addressing the child.

\section{Speech Sample}

A one minute sample of each subject's spontaneous speech was recorded and collected for data analysis. For data analysis of the adult-adult and adult-child speech samples, the first and last ten seconds of the 60 second speech sample were omitted, based upon the assumption that the middle portion would be the more representative. This left the middle 40 seconds to be extracted for further acoustical data analysis.

\section{RELIABILITY AND VALIDITY}

Reliability

In order to assess interjudge reliability, 16 of the 40 speech samples were randomly selected for replication. Eight samples were taken randomly from the mother's speech samples (four samples taken from mother-child interactions and four samples taken from mother-adult interactions). In addition, eight samples were taken randomly from the non- 
mother speech samples (four samples taken from mother-child interactions and four samples taken from non-mother-adult interactions). Technician's run-rerun reliability was accomplished by a graduate student who was unfamiliar with earlier recordings. Instructions were given on entering the 16 speech samples into the Visi-Pitch/computer via tape recorder. Specifically, the graduate student was instructed on how to start the Visi-Pitch for the selected 40 seconds of speech data. It was necessary for the technician to begin and end each speech sample at a previously chosen point, so as to eliminate the first and last ten seconds of recorded speech.

Analysis of interjudge reliability revealed that for three of the 16 speech samples chosen for reliability analysis, agreement of fundamental frequency values between technician and investigator was 100 percent. In the other 13 cases, agreement differed by $1-3 \mathrm{~Hz}$ (See Table IV).

A pilot study investigating interjudge reliability levels was performed earlier in the project, with extended average fundamental frequency found to differ by $\pm 5 \mathrm{~Hz}$. To determine intrajudge reliability, the examiner performed the same data analysis procedure on four of the 20 speech samples (two randomly selected samples from adultadult interactions and two from the adult-child 
TABLE IV

SCORESHEET FOR INVESTIGATOR AND TECHNICIAN

INTERJUDGE RELIABILITY

\begin{tabular}{|c|c|c|c|c|}
\hline Listener & subject & $\begin{array}{c}\text { Parental } \\
\text { Status }\end{array}$ & $\begin{array}{l}\text { Addressing } \\
\text { Adult } \\
\text { (Hz) }\end{array}$ & $\begin{array}{l}\text { Addressing } \\
\text { Infant } \\
\text { (Hz) }\end{array}$ \\
\hline
\end{tabular}

\begin{tabular}{|c|c|c|c|c|}
\hline $\begin{array}{l}\text { Investigator } \\
\text { Technician }\end{array}$ & 1 & Non-Mother & & $\begin{array}{l}227 \\
224\end{array}$ \\
\hline $\begin{array}{l}\text { Investigator } \\
\text { Technician }\end{array}$ & 2 & Mother & & $\begin{array}{l}229 \\
228\end{array}$ \\
\hline $\begin{array}{l}\text { Investigator } \\
\text { Technician }\end{array}$ & 3 & Mother & $\begin{array}{l}175 \\
177\end{array}$ & \\
\hline $\begin{array}{l}\text { Investigator } \\
\text { Technician }\end{array}$ & 4 & Non-Mother & & $\begin{array}{l}207 \\
204\end{array}$ \\
\hline $\begin{array}{l}\text { Investigator } \\
\text { Technician }\end{array}$ & 5 & Non-Mother & $\begin{array}{l}247 \\
250\end{array}$ & \\
\hline $\begin{array}{l}\text { Investigator } \\
\text { Technician }\end{array}$ & 5 & Non-Mother & & $\begin{array}{l}256 \\
253\end{array}$ \\
\hline $\begin{array}{l}\text { Investigator } \\
\text { Technician }\end{array}$ & 6 & Mother & $\begin{array}{l}203 \\
200\end{array}$ & \\
\hline $\begin{array}{l}\text { Investigator } \\
\text { Technician }\end{array}$ & 7 & Mother & & $\begin{array}{l}262 \\
264\end{array}$ \\
\hline $\begin{array}{l}\text { Investigator } \\
\text { Technician }\end{array}$ & 8 & Non-Mother & $\begin{array}{l}181 \\
179\end{array}$ & \\
\hline $\begin{array}{l}\text { Investigator } \\
\text { Technician }\end{array}$ & 9 & Mother & & $\begin{array}{l}207 \\
204\end{array}$ \\
\hline $\begin{array}{l}\text { Investigator } \\
\text { Technician }\end{array}$ & 10 & Non-Mother & & $\begin{array}{l}300 \\
301\end{array}$ \\
\hline $\begin{array}{l}\text { Investigator } \\
\text { Technician }\end{array}$ & 11 & Mother & $\begin{array}{l}310 \\
310\end{array}$ & \\
\hline $\begin{array}{l}\text { Investigator } \\
\text { Technician }\end{array}$ & 12 & Non-Mother & $\begin{array}{l}224 \\
225\end{array}$ & \\
\hline $\begin{array}{l}\text { Investigator } \\
\text { Technician }\end{array}$ & 16 & Mother & $\begin{array}{l}215 \\
215\end{array}$ & \\
\hline $\begin{array}{l}\text { Investigator } \\
\text { Technician }\end{array}$ & 18 & Non-Mother & $\begin{array}{l}224 \\
225\end{array}$ & \\
\hline
\end{tabular}


interactions). The investigator used the same procedures in entering recorded data into the visi-Pitch as were used with interjudge measurements. Investigator intrajudge reliability revealed a 1-2 $\mathrm{Hz}$ difference between the two readings of the selected samples (See Table V). Technician intrajudge reliability revealed a $1-3 \mathrm{~Hz}$ difference between the two readings of the selected speech samples (See Table VI). A pilot study investigating intrajudge reliability levels was done early in the project, with extended average fundamental frequency found to differ by $\pm 3 \mathrm{~Hz}$.

\section{Validity}

Since the study appears to be the first of its kind to use the real time analysis system of the computerized VisiPitch, a validity test on the instrument was performed, comparing the results with data obtained from a non-real time Kay Elemetrics Spectrum Analyzer (Digital Sona-Graph, 7800). To determine validity, the investigator extracted three randomly selected utterances within the large body of data. All the three selected utterances were between 3-5 seconds in length. The utterances were run first through the Visi-Pitch/computer system and then the Digital SonaGraph. While the computerized Visi-Pitch allows for a real time analysis of speech, the Digital Sona-Graph utilizes the more traditional method of hand counting striations displayed on a sonagram. Striations are actually lines 
TABLE V

SCORESHEET FOR INVESTIGATOR INTRAJUDGE RELIABILITY

\begin{tabular}{|c|c|c|c|}
\hline Subject & $\begin{array}{l}\text { Subject } \\
\text { Status }\end{array}$ & $\begin{array}{l}\text { Addressing } \\
\text { Adult } \\
(\mathrm{Hz})\end{array}$ & $\begin{array}{l}\text { Addressing } \\
\text { Child } \\
(\mathrm{Hz})\end{array}$ \\
\hline 1 & Non-Mother & & $\begin{array}{l}227 \\
229\end{array}$ \\
\hline 2 & Mother & & $\begin{array}{l}229 \\
231\end{array}$ \\
\hline 5 & Non-Mother & $\begin{array}{l}247 \\
245\end{array}$ & \\
\hline 11 & Mother & $\begin{array}{l}310 \\
311\end{array}$ & \\
\hline
\end{tabular}

TABLE VI

SCORESHEET FOR TECHNICIAN INTRAJUDGE RELIABILITY

$\begin{array}{clc}\text { Subject } & \text { Subject } & \text { Addressing } \\ \text { Status } & \text { Adult } \\ & & (\mathrm{Hz})\end{array}$

Addressing

Child

$(\mathrm{Hz})$

\begin{tabular}{|c|c|}
\hline 1 & Non-Mother \\
\hline 2 & Mother \\
\hline 5 & Non-Mother \\
\hline & Mother \\
\hline
\end{tabular}


resolved into their frequency components (Kay Elemetric, 1986). In order to obtain accurate fundamental frequency data on a speech sample, striations need to be clear and countable (with the aid of a magnifying glass). Upon completion of sonagrams, it was found that two of the three displays could not be hand counted. This was due to the poor clarity of the graphic display. Validity judges were unable to count the striations and perform necessary calculation. Therefore, they were unable to calculate a fundamental frequency for those utterances. Only one of the three proved clear enough to count striations. Using the Visi-Pitch, average fundamental frequency for the utterance was found to be $194 \mathrm{~Hz}$. When using the Sona-Graph, the four validity judges hand counting striations and calculated fundamental frequency to be: $193 \mathrm{~Hz}, 195 \mathrm{~Hz}, 189 \mathrm{~Hz}$ and 186 $\mathrm{Hz}$, respectively. Half of these sonagraphic results were found to be within $2 \mathrm{~Hz}$ of the Visi-Pitch results.

\section{STATISTICAL ANALYSIS}

Data analysis included a comparison between mothers and non-mothers use of average fundamental frequency and frequency range both when speaking to an adult and when speaking to an infant. To determine the significant difference between average fundamental frequency used by mothers when addressing the infant and when addressing the 
adult, a one-tailed t-test was used for dependent measures. This same type of t-test was used to determine the significant difference between average fundamental frequency used by non-mothers when addressing the infant and the adult. A one-tailed t-test for independent measures was chosen: (a) to determine the significant difference between mothers fundamental frequency and non-mothers fundamental frequency when addressing an adult and (b) to determine the significant difference between mothers fundamental frequency and non-mothers fundamental frequency when addressing the infant. 


\section{CHAPTER IV}

\section{RESULTS AND DISCUSSION}

\section{RESULTS}

This study was conducted to determine the capability of a real time computerized Visi-Pitch to reflect elevation of fundamental frequency and expansion of frequency range by female adults when addressing infants.

The first question asked in this study was: Does the average fundamental frequency used by mothers when speaking to infants differ significantly from the average fundamental frequency used in adult-adult interactions? Results of this study revealed that average pitch for the ten mothers when addressing adults was $213.7 \mathrm{~Hz}$. The average pitch used by the mothers when speaking to the infant was $228.7 \mathrm{~Hz}$. Seventy percent of the mothers used a higher pitch when addressing the child as compared to when they spoke to the adult. It was predicted that mothers would use a higher pitch when addressing the child. This prediction was based on findings by Bernstein Ratner and Pye (1984); Garnica (1974 and 1977); Remick (1971); and Stern et al. (1983). In order to test this prediction, a one-tailed t-test was performed. A t-test for dependent measures showed that for 
the average of the ten mother's fundamental frequency, pitch used when addressing the child was not significantly higher $(t=.67, d f=9$, (NS)) than pitch used to the adult. It must be noted that although this elevation in pitch did not reach conventional levels of significance, average pitch used when addressing infants was elevated by $15 \mathrm{~Hz}$. The results are presented in Table VII and Figure 1.

The second question was: Does the average fundamental frequency used by non-mothers when speaking to infants differ significantly from the average fundamental frequency used in adult-adult interactions? A comparison was made between non-mothers speech to adults versus speech to infants, similar to the Jacobsen et al. (1983) study. The difference between pitch used in the two test situations was quite large $($ mean $=207 \mathrm{~Hz}$ when speaking to adults; mean = 243.8 $\mathrm{Hz}$ when speaking to infants). The difference in average pitch used during the two listener sessions ( 36.8 $\mathrm{Hz}$ ) was found to be significant $(t=3.18, \mathrm{df}=9, \mathrm{p}=\leq .01$, one-tailed). The results are presented in Table VIII and Figure 2 .

The third question asked was: Does the average fundamental frequency used by mothers when speaking to adults differ significantly from the average fundamental frequency used by non-mothers when speaking to adults? A $t$ test for independent measures revealed no statistically 


\section{TABLE VII}

COMPARISON OF MOTHERS FUNDAMENTAL FREQUENCY

WHEN ADDRESSING ADULTS VERSUS CHILDREN

\begin{tabular}{llllll}
\hline & $\begin{array}{c}\text { Mean } \\
(\mathrm{Hz})\end{array}$ & S.D. & $\begin{array}{c}\text { Differences } \\
\text { of Means } \\
(\mathrm{Hz})\end{array}$ & $t$ & $\mathrm{p}$ \\
\hline & & & & & \\
Adult & 213.7 & 37.33 & 15 & 0.67 & 0.60 \\
Infant & 228.7 & 40.56 & & & \\
\hline
\end{tabular}

\section{TABLE VIII}

COMPARISON OF NON-MOTHERS FUNDAMENTAL FREQUENCY WHEN ADDRESSING ADULTS VERSUS CHILDREN

\begin{tabular}{llclll}
$\begin{array}{c}\text { Mean } \\
(\mathrm{Hz})\end{array}$ & S.D. & $\begin{array}{c}\text { Differences } \\
\text { of Means } \\
(\mathrm{Hz})\end{array}$ & $t$ & $p$ \\
\hline
\end{tabular}

$\begin{array}{llllll}\text { Adult } & 207 & 22.90 & & & \\ \text { Infant } & 243.8 & 26.89 & 36.8 & 3.18 & .01\end{array}$




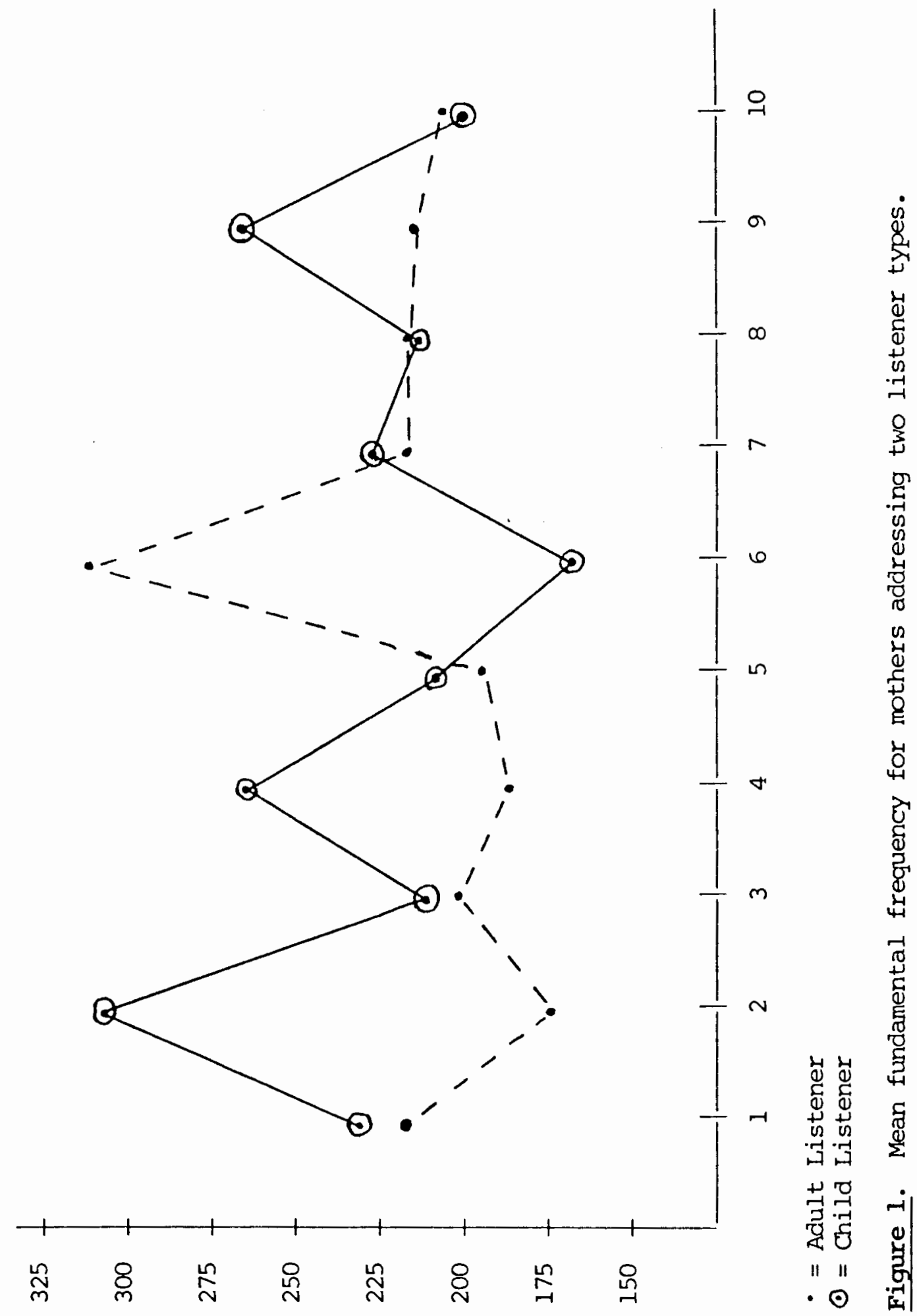




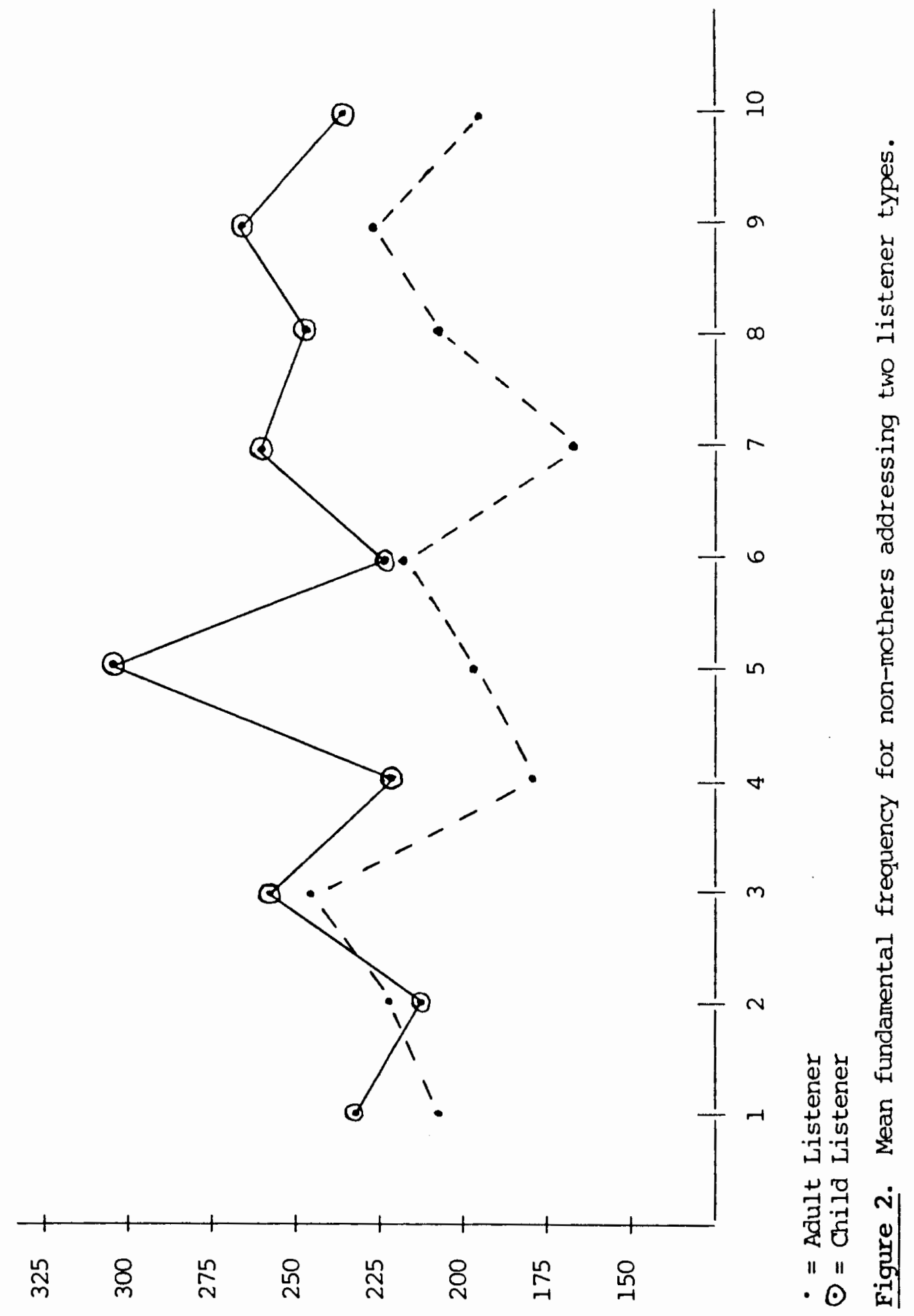


significant difference between mothers and non-mothers addressing the adult listener $(t=.48$, df $=18$, NS). It appeared that mothers $(213.7 \mathrm{~Hz})$ used a non-significantly higher mean fundamental frequency than non-mothers $(207 \mathrm{~Hz})$, when addressing the adult, reflecting a $6.7 \mathrm{~Hz}$ difference (refer to Table IX).

The fourth question asked was: Does the average fundamental frequency used by mothers when speaking to children differ significantly from the average fundamental frequency used by non-mothers when speaking to children? A comparison was made of average pitch mothers use when speaking to the infant (mean pitch $=228.7 \mathrm{~Hz}$ ) and nonmothers use when addressing the infant (mean pitch $=243.8$ $\mathrm{Hz})$. A t-test for independent measures revealed that this $15 \mathrm{~Hz}$ difference was not statistically significant $(t=.98$, $d f=18$, NS) ( see Table $X)$.

The above four questions dealt with fundamental frequency. The four questions pertaining to frequency range were not subjected to statistical analysis due to the fact that spurious data points indicating frequencies exceeding the known possible range of adult female voices. This was verified by independent analysis of frequency range raw data by the product specialist for Kay Elemetrics. 
TABLE IX

COMPARISON OF MOTHER AND NON-MOTHERS FUNDAMENTAL FREQUENCY WHEN ADDRESSING ADULTS

\begin{tabular}{|c|c|c|c|c|c|}
\hline & $\begin{array}{c}\text { Mean } \\
(\mathrm{Hz})\end{array}$ & S.D. & $\begin{array}{c}\text { Differences } \\
\text { of Means } \\
(\mathrm{Hz})\end{array}$ & $t$ & $\mathrm{p}$ \\
\hline Mother & 213.7 & 37.33 & \multirow{2}{*}{6.7} & \multirow{2}{*}{.48} & \multirow{2}{*}{.70} \\
\hline Non-Mother & 207 & 22.90 & & & \\
\hline
\end{tabular}

TABLE X

COMPARISON OF MOTHERS AND NON-MOTHERS FUNDAMENTAL FREQUENCY WHEN ADDRESSING CHILDREN

\begin{tabular}{|c|c|c|c|c|c|}
\hline & $\begin{array}{c}\text { Mean } \\
(\mathrm{Hz})\end{array}$ & S.D. & $\begin{array}{c}\text { Differences } \\
\text { of Means } \\
(\mathrm{Hz})\end{array}$ & $t$ & $\mathrm{p}$ \\
\hline Mother & 228.7 & 40.56 & & & \\
\hline Non-Mother & 243.8 & & $15 \mathrm{~Hz}$ & .98 & .40 \\
\hline
\end{tabular}




\section{DISCUSSION}

The present study was designed to investigate empirically the capability of the computerized Visi-Pitch to reflect elevation in fundamental frequency and expansion in frequency range in adult females. It was hypothesized that, when investigating these two acoustical features of motherese, a real time computerized Visi-Pitch would yield results similar to those studies utilizing subjective judgement, non-real time, and other real time forms of analysis. Results of this study did not support the hypothesis.

Questions raised earlier in this project regarding mothers and non-mothers use of frequency range could not be statistically answered due to questionable face validity for this acoustic parameter. Frequency range values computered by the Visi-Pitch appeared to be in question when analyzing low frequency points in the speech samples. This author began to question data obtained for the low points of the frequency range data points as early as the pilot study. Numerous inquires were made to the Visi-Pitch manufacturer regarding frequency range data. Despite continued communication and assurance from the product specialist, problems persisted with regard to outcomes for the low end of the frequency range. Finally, after the study's data were gathered, the product specialist for Kay Elemetrics 
substantiated these data by agreeing that all ten samples submitted for analysis contained spurious or questionably spurious low frequency points and were noted to be "too low for a female" (Paul Arcell, personal letter, May 10, 1988). In addition, the product specialist performed an analysis of female speech and reported similar "garbage data" (Paul Arcell, personal letter, May 10, 1988). By approved procedures, he obtained frequency range data outside the female range. He further pointed out that obtaining accurate frequency range values can be tricky as "...even one low pulse will contaminate the data" (Paul Arcell, personal letter, May 10, 1988). The solution offered for the dilemma was to manually scan the data and use the cursor to work around values or data points that were suspected of being incorrect. In effect, after the fact, he recommended that one subjectively determine when data points seemed to be outside the limits of a female's voice. Thus, he concluded, if one were to manually eliminate the spurious data points it would increase the reliability levels. In short, the equipment does not do what its manufacturer purported that it would do. Thus, frequency range values could not be compared to other acoustical research studies. When examining fundamental frequency data analyzed by the computerized Visi-Pitch, it was found that pitch shifting by mothers and non-mothers did occur in the same 
direction as in other studies (Fernald and Simon, 1984; Garnica, 1974 and 1977; Jacobsen et al., 1983; and WarrenLeubecker and Bohannon, 1984) but was not as pronounced (see Table 11). The average pitch used by all mother subjects when addressing the child was raised by an average of $15 \mathrm{~Hz}$ as compared to the adult-adult interaction. Non-mothers were found to raise their pitch when speaking to the child by an average of $36.8 \mathrm{~Hz}$. This study illustrated that the Visi-Pitch provided pitch data that reflected pitch shifting in the same direction as in other motherese studies; however, these findings should be interpreted conservatively. Possible design flaws may have influenced this investigator's results.

One design flaw may have been the inclusion of a mother whose voice, under testing situations, was not representative of the larger population of mothers. Analysis of this subject's voice revealed a pitch of $165 \mathrm{~Hz}$ used when addressing the child. A fundamental frequency this low could not be considered sex-appropriate (a criterion for inclusion in the study). Additionally, this subject used a rather pronounced increase in pitch (311 Hz) during the adult-adult interaction (see Table XI, subject \#11). It appeared that this woman's voice represented more than just pitch shifting. Contamination of the data could have occurred due to the presence of ambient noise (e.g.. 
TABLE XI

FUNDAMENTAL FREQUENCY USED BY ADULT FEMALES

IN TWO LISTENER SITUATIONS

\begin{tabular}{|c|c|c|}
\hline$\underset{\#}{\text { Subject }}$ & $\begin{array}{c}\text { Parental } \\
\text { Status }\end{array}$ & $\begin{array}{c}\text { FO Used by Subjects }_{0} \\
\text { When Speaking } \\
\text { to Adult } \\
(\mathrm{Hz})\end{array}$ \\
\hline
\end{tabular}

$F_{0}$ Used by Subjects When Speaking

to Child

$(\mathrm{Hz})$

\begin{tabular}{rccc}
\hline \hline & & & \\
1 & Non-Mother & 205 & 229 \\
2 & Mother & 220 & 232 \\
3 & Mother & 175 & 307 \\
4 & Non-Mother & 223 & 210 \\
5 & Non-Mother & 246 & 253 \\
6 & Mother & 201 & 209 \\
7 & Mother & 186 & 263 \\
8 & Non-Mother & 179 & 222 \\
9 & Mother & 191 & 206 \\
10 & Non-Mother & 199 & 301 \\
11 & Mother & 311 & 165 \\
12 & Non-Mother & 221 & 222 \\
13 & Non-Mother & 169 & 260 \\
14 & Mother & 217 & 226 \\
15 & Non-Mother & 204 & 246 \\
16 & Mother & 216 & 215 \\
17 & Mother & 215 & 266 \\
18 & Non-Mother & 226 & 264 \\
19 & Non-Mother & 198 & 231 \\
20 & Mother & 205 & 198 \\
& & & \\
\hline
\end{tabular}

subject laughter). The subject used frequent high pitched giggling when she spoke to the investigator. Since the Visi-Pitch averages out all voiced stimuli between 50 and $1600 \mathrm{~Hz}$ for each second of voicing, it appeared these vocal insertions were also averaged, thus yielding pitch outcomes that represented more than maternal pitch shifting. In 
light of these finding it can be argued that a 40 second speech sample allows for greater possibility of contamination of the actual speech data. It appeared that the computerized Visi-Pitch was often unable to distinguish speech from other noises (e.g. laughter, coughing, whispers, etc.), thus, inappropriately extending pitch levels. By using a 40 second sample, this investigator was unable to provide for a greater control over the data used in the acoustical data analysis.

In addition to the inappropriate mother subject, it was noted that three additional subjects (one non-mother and two mothers) used their habitual pitch or actually lowered their pitch when addressing the child. It was apparent that these subjects did not follow expected pitch shifting. Findings similar to this investigation may have been found in other motherese studies; however, due to small sample size utilized in this study, outcomes were altered more. Sample size, no doubt, significantly altered the outcome of this study as reflected by a large standard deviation noted in the mother subject group (Table VII, p. 36).

The findings that mothers and non-mothers pitch levels did not differ significantly from one another while they spoke to both listeners is consistent with the literature (Jacobsen et al., 1983; Snow and Ferguson, 1977). If pitch shifting is universal, pitch shifting should occur in the 
same direction and with similar magnitude for both mother and non-mother speakers, with allowances made for individual vocal fold variation of mass, size, and elasticity (Borden and Harris, 1980). While both mothers and non-mothers exhibited pitch shifting in the same direction as in the literature, it was surprising to find that non-mothers used greater elevation in pitch than mothers when addressing the child listener. It was found that four of the ten mothers elevated their pitch with the magnitude as in other motherese studies (Fernald and Simon, 1984); Garnica, 1974 and 1977; Warren-Leubecker and Bohannon, 1984). The remaining four mothers that exhibited pitch shifting raised their fundamental frequency by $8-15 \mathrm{~Hz}$ when addressing the child. Several variables could be attributed to this lack of significant elevation: use of a 40 second speech sample, presence of ambient noise, questionable validity of the apparatus, or the presence of vocal behavior in addition to pitch elevation may have reduced the "strength" of the outcomes.

Several of these variables could have been eliminated by reducing length of speech samples while providing for repeated measures of pitch using real words and phrases, similar to the Garnica (1974) study. Even after controlling for the above variables, the question still remains in regard to letting the Visi-Pitch run for the full 40 
seconds. This is noted, after the fact, to be a design flaw of the study.

Finally, from this study some serious questions were regarding the appropriateness of the computerized Visi-Pitch to extract frequency range data arose. As for fundamental frequency, the equipment does seem to have the capability to follow appropriate trends similar to existing research; however, due to possible design flaws, coupled with the small sample size, it was difficult to draw strong conclusions about the machine's ability to represent fundamental frequency in running speech. 
CHAPTER V

\section{SUMMARY AND IMPLICATIONS}

\section{SUMMARY}

With commercial availability of non-real and real-time spectrum analyzers, the speech-language pathologist has the means to objectively extract and measure pitch taken from speech samples. Though both types of spectrum analyzers provide the clinician with viable methods of measuring fundamental frequency and frequency range values, pitch extraction using real time allows for greater efficiency in acoustic measurements. The Kay Elemetrics Visi-Pitch is one such real-time spectrum analyzer that is less expensive and more accessible than other real time speech science hardware. The purpose of this study was to investigate the capability of a computerized Visi-Pitch to reflect elevation of fundamental frequency and expansion of frequency range by female adults.

Ten mothers and ten non-mothers, between the ages of 20 and 40, were used as subjects in the study. In addition to this subject group, ten of the mother's infants between the ages of 4.0 and 8.0 months of age were used as listeners in the study. Sixty second speech samples were elicited 
from the female adults while they spoke to: 1) the investigator, and 2) the infant. Forty seconds of these samples were analyzed through a computerized visi-Pitch in order to determine average fundamental frequency (pitch) and frequency range in each speaking situation.

Analysis of fundamental frequency revealed that both adult subject groups (mothers and non-mothers) elevated their pitch when addressing the child, in comparison to the adult-adult interaction. A one-tailed t-test for dependent measures was used to determine the significant difference between average funamental frequency used by mothers when addressing the infant and the adult. The same type of $t$ test was used to determine differences between average fundamental frequency used by non-mothers when addressing the child and the adult. Statistical analysis revealed that for the average of the ten mothers fundamental frequency, pitch used when addressing the child was not significantly higher than pitch used to the adult. The average pitch used by mother subjects when addressing the child was elevated by $15 \mathrm{~Hz}$. In terms of fundamental frequency outcomes used by non-mothers addressing the two listeners, it was found that non-mothers elevated their pitch by an average of $36.8 \mathrm{~Hz}$, a statistically significant difference.

A $t$-test for independent measures was used when comparing mothers and non-mothers fundamental frequency when 
addressing the adult listener. Statistical analysis of the data revealed no significant difference between mothers and non-mothers use of pitch when speaking to the adult. Similarly, analysis of pitch levels used by mothers (228.7 $\mathrm{Hz}$ ) and non-mothers $(243.8 \mathrm{~Hz})$ when addressing the infant listener was found not to be statistically significant. While it appeared that the computerized Visi-Pitch allows for comparison and analysis of fundamental frequency data, the instrument provided questionable frequency range results. Low points of frequency range were not subjected to statistical analysis due to spurious data points at the low end of frequency range, which exceeded the known range of normal adult female voices.

Results of this study revealed that the real time computerized Visi-Pitch has the capability to demonstrate the use of adult female pitch shifting in the same direction as other motherese studies; however, it was found that this instrument is an inadequate tool for frequency range analysis.

It was concluded that more solid evidence on the validity of frequency range outcomes needs to be disseminated by the Visi-Pitch manufacturer before this instrument can be considered of value to the researcher. 


\section{IMPLICATIONS}

Based on the outcomes of this study, the following suggestions are offered for future investigations: 1) establish validity for low point of frequency range values when using the Visi-Pitch to investigate frequency range; 2) reduce speech sample length; 3 ) increase the number of subjects per group; and 4) reduce subject awareness of the testing situation.

As questions were raised on the capability of the computerized Visi-Pitch to reflect frequency range, it is imperative that Kay Elemetrics re-evaluate the validity of the equipment to measure low points of frequency range data. If the manufacturer's assessment of the machine yields results consistent with this author's results, the question can be raised: Can the computerized Visi-Pitch be modified in order to more accurately analyze frequency range? Until this question can be fully addressed by the manufacturer, future acoustical researchers should seek other forms of real time spectrum analysis system or non-real time systems.

Reducing the length of the speech samples is suggested for future research in order to allow for greater control over input of data into the spectrum analyzer. Analyzing a smaller segment of speech (less than 40 seconds) may possibly reduce the chance of ambient noise contaminating 
the data and thus, inappropriately extending pitch levels due to inappropriate data points.

In conjunction with reducing the number of seconds of speech used in the analysis, increasing the number of subjects used per group would provide for better design of future studies. Due to small sample size, the results of this study were often difficult to interpret and generalize to the adult female population. Future endeavors would find interpretation easier if a larger group of mothers and nonmothers were used as subjects.

Finally, subject awareness of the recording of speech may have affected some subject's ability to communicate naturally with both investigator and child. Future investigators may find that minimizing the presence of the investigator and the audio taping equipment while taping speech will reduce feelings of anxiety in subjects. Awareness of testing may be reduced by involving the subject in a task such as reading several sentences, similar to the Jacobsen et al. study (1983). Additionally, the use of a one-way mirror coupled with an inobtrusive microphone may create an environment conducive to more natural interaction. In conclusion, the questions raised as a result of this study create a need for Kay Elemetrics to re-evaluate the capabilities of the Visi-Pitch to accurately analyze frequency range data. Additionally, suggestions are offered 
to future researchers in order to reduce design variables that may have influenced the results of this study. 


\section{BIBLIOGRAPHY}

Berko-Gleason, J. (1973). Code switching in children's language. In T.E. Moore (Ed.), Cognitive development and acquisition of language. New York: Academic Press.

Bernstein Ratner, N. and Pye, C. (1984). Higher pitch in BT is not universal; acoustic evidence from Quiche Mayan. Journal of Child Language, 11, 515-522.

Blout, B. and Padgug, E. (1977). Prosodic, paralinguistic, and interactional features in parent-child speech: English and Spanish. Journal of Child Language, 4 , 67-86.

Borden, G. and Harris, K. (1980). Speech science primer. Baltimore: William and Wilkins Company.

Drach, K. (1969). The language of the parents: A pilot study. (Language-Behavior Laboratory Paper 14). Berkeley: University of California.

Ferguson, C. (1964). Baby talk in six languages. American Anthropologist, 66 ( 6 part 2$), 103-114$.

Fernald, A. and Simon, T. (1984). Expanded intonation contours in mother's speech to newborns. Developmental Psychology, 20, 104-113.

Garnica. O. (1974). Some characteristics of prosodic input to young children. Unpublished doctoral dissertation, Stanford University.

Garnica. O. (1977). Some prosodic and paralinguistic features of speech to young children. In $C$. Snow and C. Ferguson (Eds.), Talking to children: Language input and acquisition. New York: Cambridge University Press.

Jacobson, T.L., Boersma, D., Fields, R. and Olson, K. (1983). Prelinguistic features of adult speech to infants and small children. Child Development, 54, $546-442$. 
Kay Elemetrics (1986). Digital Sona-Graph. Pine Brook, New Jersey: Kay Elemetrics Corp.

Kay Elemetrics (1986). Visi-Pitch Products: Clinical Tools for Speech. Pine Brook, New Jersey: Kay Elemetrics Corp.

Kelkar, A. (1964). Marathi baby talk. Word, 20, 40-54.

Nicolosi, L., Harryman, E. and Kresheck, J. (1983).

Terminology of communication disorders. Baltimore: Williams and wilkins.

Remick, H. (1971). The maternal environment of linguistic development. Unpublished doctoral dissertation, University of California, Davis.

Ruke-Dravina, V. (1977). Modifications of speech addressed to young children in Latvian. In $C$. Snow and $C$. Ferguson (Eds.), Talking to children: Language input and acquisition. New York: Cambridge University Press.

Sachs, J., Brown, R. and Salerno, R. (1976). Adults' speech to children. In $W$. von Raffler-Engel and $Y$. Legrun (Eds.), Baby talk and infant speech. Lisse, Netherlands: Swets and Zeitlinger.

Snow, c. (1977). The development of conversation between mothers and babies. Journal of Child Language, $4,1-$ 22 .

Snow, C. and Ferguson, C. (1977). Talking to children: Language input and acquisition. New York: Cambridge University Press.

Stemple (1984). Clinical voice pathology (theory and management). Baltimore: Charles E. Merrell Publishing Co.

Stern, D., Spieker, S., Barnett, R. and MacKain, K. (1983). The prosody of maternal speech: Infant age and context related changes. Journal of Child Language, 10, $1-15$.

Warren-Leubecker, A. and Bohannon, J. (1984). Intonation patterns in CDS: Mother-father differences. Child Development, 55, 1379-1385. 


\section{APPENDIX A}

PUBLIC NOTICE

\section{ATTENTION MOTHERS}

I am seeking mothers (ages 20 to 40 years old) with an infant (four to eight months) who would be willing to contribute ten minutes of their time to advance science.

I am doing a study of how adults communicate with prelanguage infants. You will be expected to talk to an investigator and then to your child for about one minute each. If interested please contact me at the speech and hearing clinic, PSU (464-3533) or home (224-9224).

Thank you,

Denise Clemens

Graduate Student 


\section{APPENDIX B}

\section{COVER LETTER}

Dear Subjects:

I am a graduate student at Portland state University conducting a study investigating the ways adults interact with young children. I am investigating the ways mothers and non-mothers (ages 20 to 40 years) talk to infants in the 4.0 to 8.0 age range.

This study will be accomplished by a two minute audiotaped conversation talking to me and the to a/your child. The tape recording will be done at Portland state University at a time mutually convenient for you and the department. Names will not be used in reporting the results and the audiotapes will only be available to authorized University personnel. Any participant may be excused from participation from this study at any time without penalty. Prior to the tape recorded sessions, you will be given a brief hearing screening test.

I you experience problems that are the result of your participation or potential participation in this study, please contact Robert Tinnin, Office of Graduate studies and Research, 105 Neuberger Hall, Portland State University, 464-3423.

Please complete the information on the attached sheet, indicating your approval and willingness for you or your family to participate in this study, and return this form to me immediately in the envelope provided. It is important that I schedule the taping session as soon as possible. Please call me at 224-9224 (home) or 464-3533 (PSU) if you have any questions. I appreciate your cooperation.

sincerely, 


\section{APPENDIX C}

\section{CONSENT LETTER}

\section{SUBJECT'S NAME:}

TELEPHONE :

1. Do you have any children between the ages of 4.0 and 8.0 months? (If yes, complete question $\$ 2$. )

2. CHILD'S NAME:

\section{BIRTHDATE: $\quad$ AGE :}

I understand that this research project will investigate the ways adults talk to young children. This study will be conducted by Denise clemens under the supervision of Dr. Robert Casteel.

I understand that the study involves me speaking to an investigator and then to a/your child for about one minute each. I understand that each conversation will be tape recorded. My child will listen to me and listen to another adult talk for the allotted time.

It has been explained to me that the purpose of the study is to learn nore about how adults talk to children who have not yet learned language.

Ms. Denise Clemens and Dr. R. Casteel have offered to answer any questions $I$ may have about the study and what is expected of me in the study. I have been assured that all information I give will be kept confidential and that the ldentity of all subjects will remain anonymous.

I understand that I am free to withdraw from participation in this study at any time without jeopardizing ny course grade or my relationship with Portland state University.

I have read and understand the foregoing information. I hereby agree to serve as a subject and (if applicable) give my permission for my child to participate in the study. 


\section{APPENDIX D}

\section{INSTRUMENTATION TECHNICAL DATA}

TAPE RECORDERS:

Ar-Tik' Model 414

Tandberg Series 9200XD

MICROPHONE :

Ar-Tik' Brand Microphone

SPECTRUM ANALYZERS :

Real Time

Kay-Elementrics Visi-Pitch Model 6087DS

Non-Real Time

Kay-Elementrics Digital Sona-Graph Model 7800 
APPENDIX E

SAMPLE COMPUTERIZED VISI-PITCH DISPLAY

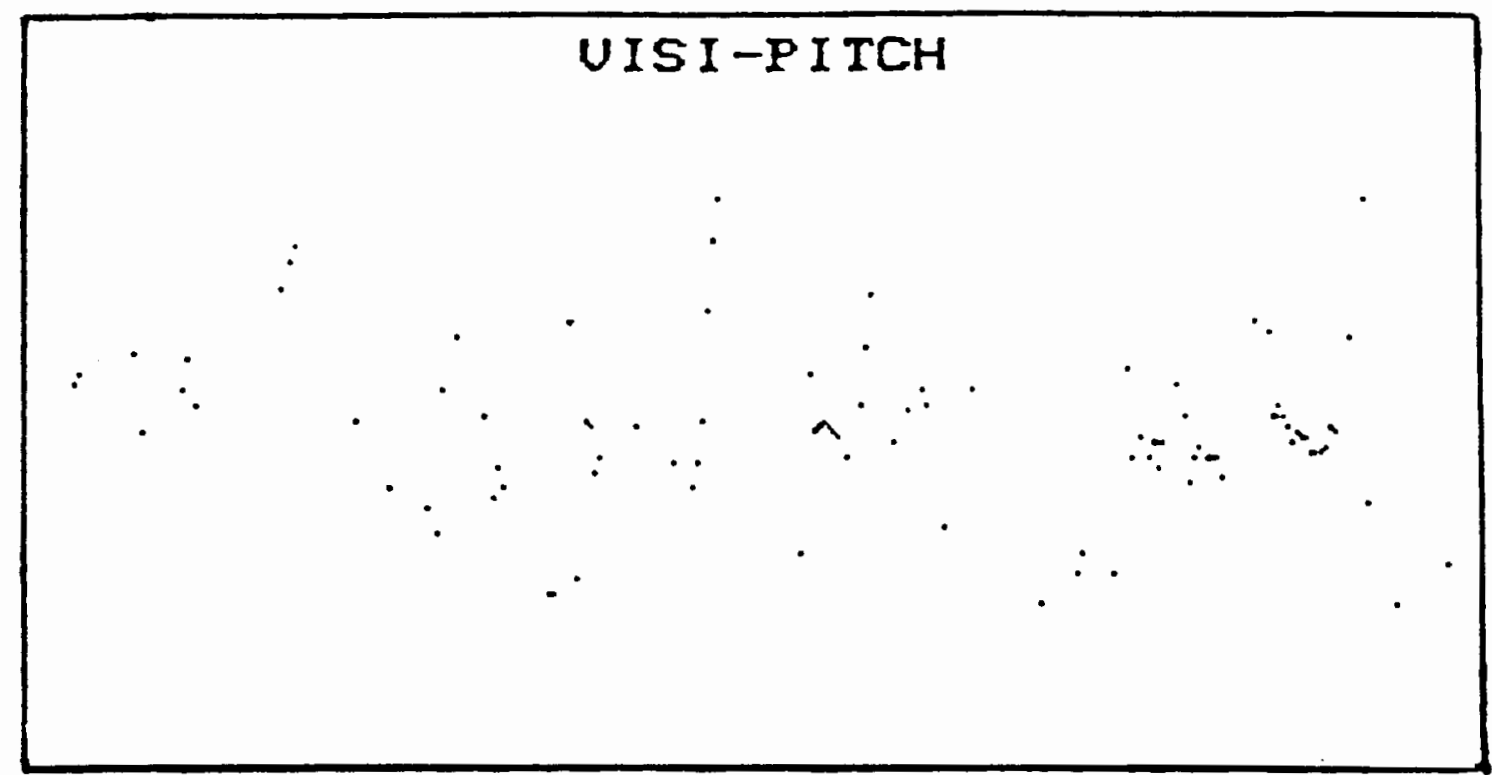

IRIGGER MOTMEl/Cont inuaus

ianisis jomxelloverur ite

SCREEN Lower Uupperymi

CURSOR Lise/Right/Horz 


\section{APPENDIX F}

SAMPLE COMPUTERIZED VISI-PITCH READOUT

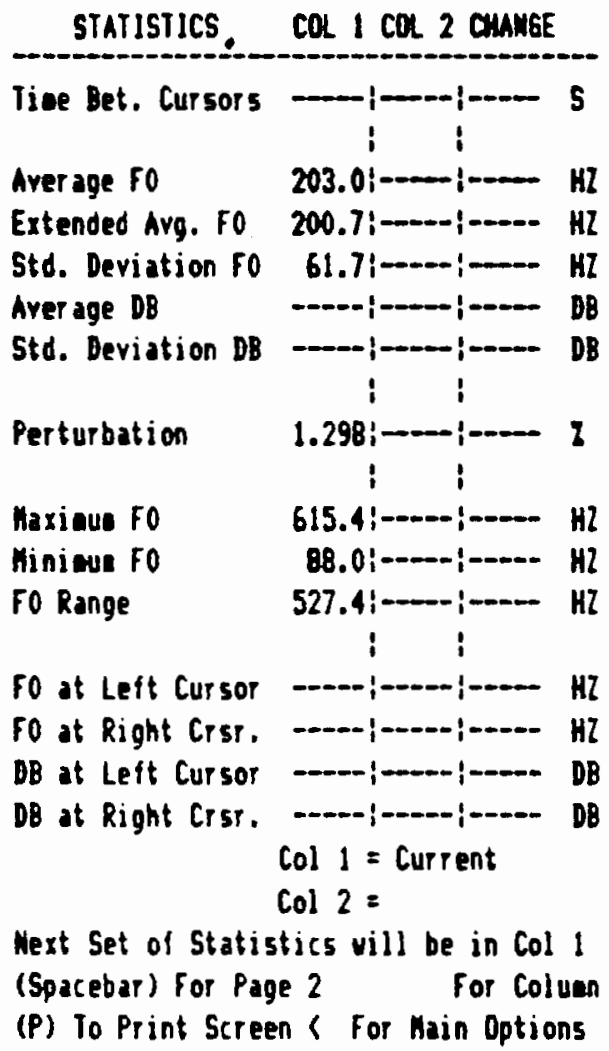




\section{APPENDIX G}

\section{VERBAL INSTRUCTIONS TO SUBJECTS}

"I would like you to talk for one minute about this plastic ball. You can tell me anything about the color, the shape, the size, or any other thing that it brings to mind. Please continue describing the object until I tell you to stop." 